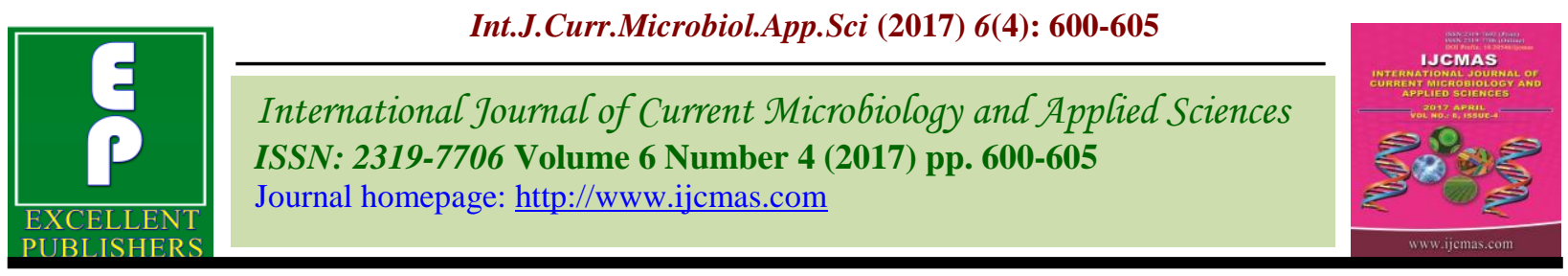

Original Research Article

https://doi.org/10.20546/ijcmas.2017.604.072

\title{
Evaluation and Efficacy of the Antibacterial Activity of Silver and Gold Nanoparticles Synthesize from Camelus dromedarius (Camel) Milk against Oral Pathogenic Bacteria
}

\author{
Kamini Parmar* and O.P. Jangir \\ Department of Biotechnology, Maharaja Vinayak Global University, Jaipur, Rajasthan, India \\ *Corresponding author
}

\begin{tabular}{|c|c|}
\hline & A B S T R A C T \\
\hline & \multirow{5}{*}{$\begin{array}{l}\text { The unique property of the silver and gold nanoparticles having antibacterial activity drags } \\
\text { the major attention towards the present nanotechnology. Synthesis of nanobodies is of } \\
\text { great interest in the development of nanotechnological tool for biomedical applications. } \\
\text { This study investigates a competent and sustainable route of AgNP and AuNP preparation } \\
\text { using Camel milk, well adorned for their wide availability and healing property. The silver } \\
\text { and gold nanoparticles were examined by UV-visible spectroscopy (Systonic 2203) that } \\
\text { demonstrated a peak at } 446 \text { and } 551 \mathrm{~nm} \text { respectively. Scanning electron microscopy (SEM- } \\
\text { Zeiss) and Transmission electron microscopy (TEM-FEI Tecnai G2 S-Twin) analysis } \\
\text { showed that the size of the synthesized spherical AgNPs ranged from } 200 \text { to } 300 \mathrm{~nm} \text { and } \\
\text { size of roughly spherical shaped AuNP in cluster ranged from } 100 \text { to } 150 \mathrm{~nm} \text {. Further, the } \\
\text { antibacterial activity of silver and gold nanoparticles was evaluated by well diffusion } \\
\text { method in vitro, and it was found that these biogenic nanoparticles have antibacterial } \\
\text { activity against Streptococcus mutans (MTCC 1890) and Staphylococcus aureus (MTCC } \\
\text { 7443). }\end{array}$} \\
\hline Keywords & \\
\hline $\begin{array}{l}\text { Camel milk, } \\
\text { Nanoparticles, } \\
\text { SEM, TEM, } \\
\text { Antibacterial } \\
\text { activity. }\end{array}$ & \\
\hline Article Info & \\
\hline $\begin{array}{l}\text { Accepted: } \\
\text { 06 March } 2017 \\
\text { Available Online: } \\
10 \text { April } 2017\end{array}$ & \\
\hline
\end{tabular}

\section{Introduction}

Nanotechnology is mainly apprehensive with the synthesis of nanoparticles and their application in various fields of medicine, physics, materials science, chemistry, and engineering. An imperative aspect of nanotechnology concerns the improvement of experimental processes for the synthesis of nanoparticles of different sizes, shapes and controlled dispersity (Kumar et al., 2013). Metal nanoparticles such as gold (Au) and silver (Ag) have been familiar since ancient times due to their ornamental and medicinal applications (Gopalkrishnan et al., 2014). It is well- known the NPs have antibacterial activity. A nanoparticle holds effective role in the killing and inhibiting the bacterial growth because of their large surface area, hence providing better contact with microorganisms (Nelson Duran et al., 2010). And also have recognized importance in chemistry, physics, and biology because of their unique optical, electrical, and photo thermal properties (Rimal et al., 2013).

These metallic nanostructures are reported to have their prospective applications in anticancer drug delivery (Brown et al., 2010), catalysis, sensors (Manivannan et al., 2011), wound dressing (Leaper, 2006), medical imaging (Muthu et al., 2010), and 
antibacterial activity (Sathiskumar et al., 2009).

Dental caries, the most widespread diseases affecting mankind, involve the adherence of bacteria and development of biofilm on both the natural and restored tooth surface. It is a localized, progressive demineralization of the firm tissues of the crown (coronal enamel, dentine) and root (cemaentum, dentine) surfaces of teeth (Allaker, 2010). This is a worldwide public health problem for which Streptococcus mutans has been identified as the possible infectious etiology. The various antibacterial agents have been proved to be efficient in controlling the growth of $\mathrm{S}$. mutans but showed condensed efficiency in controlling the parameters responsible for dental problems (Holla et al., 2012; Sierra et al., 2008).

Use of camel milk as a traditional medicine is one of the frequent practice in India due to their wide application in biomedical field. It is used for the treatment of several diseases and contains strong antibacterial activity. It is reported to have a stronger inhibitory system than that of cow's milk (EI Agamy, 1992). Nutritional value of camel milk mention below: (Wernery, 2007).

Present project proposed with the aim of synthesis and characterization of silver and gold nanoparticles from camel milk and evaluation of the anti-bacterial activity against acid producing bacteria streptococcus mutans. This is the first report where camel milk was found to be an appropriate source for the synthesis of silver and gold nanoparticles.

\section{Materials and Methods}

\section{Material}

All chemical reagents including chloroauric acid $\left(\mathrm{HAuCl}_{4}\right)$ and silver nitrate $\left(\mathrm{AgNO}_{3}\right)$ (CDH, Central Drug House, New Delhi) were obtained and used as received. All the chemicals used were of the highest purity available. Ultrapure water was used for every experiments (Milli-Q System; Millipore Corp.).

\section{Sample collection}

Camel milk sample was collected from Camel Research Centre of Bikaner (Rajasthan) (Table 1).

\section{Synthesis of gold nanoparticles}

Firstly we were collect fresh camel milk then make serial dilution $10^{-1}$ and $10^{-2}$ with distilled water. $5 \mathrm{ml}$ of $10^{-2}$ dilution was added to the 5 $\mathrm{ml}$ of chloroauric acid solution $(1 \mathrm{mM})$. This solution mixture was exposed to direct sunlight for 2 hours and change in the color was observed.

\section{Synthesis of silver nanoparticles}

Firstly we were collect fresh camel milk then make serial dilution $10^{-1}$ and $10^{-2}$ with distilled water. $1 \mathrm{ml}$ of $10^{-2}$ dilution was added to the 9 $\mathrm{ml}$ of silver nitrate solution. This solution mixture was exposed to direct sunlight for 30 minutes and change in the color was observed.

\section{Characterization of synthesized nanoparticles}

The silver and gold nanoparticles obtained from camel milk were characterized by recording UV-Vis absorption spectra using Double Beam UV-visible spectrophotometer 2203 through a quartz cell with $10 \mathrm{~mm}$ optical path that demonstrated peak value respectively. The samples were packed in a quartz cuvette of $1 \mathrm{~cm}$ light- path length, and the light absorption spectra were given in reference to deionized water. 
The morphology of the colloidal sample was examined using Scanning electron microscopy (SEM-Zeiss) and Transmission electron microscopy (TEM-FEI Tecnai G2 STwin), with ultrahigh resolution (UHR) pole piece operating at an accelerating voltage of $300 \mathrm{kV}$ that revealed size and shape.

\section{Results and Discussion}

This work is focused on the synthesis of gold and silver nanoparticles with an environmentally friendly biosynthetic method. Both silver and gold nanoparticles were synthesized using Camel milk under the sun light. Due to the reaction of the metal salt and milk sample, colour of the solutions changed colorless to yellow and dark brown, indicating the formation of silver and gold nanoparticles, respectively (Fig. 1).

\section{UV visible studies}

UV-Vis spectroscopy is an important technique to establish the formation and stability of metal nanoparticles in aqueous solution. Reduction of silver ions into silver nanoparticles using camel milk was evidenced by the visual change of color from colorless to intense yellow due to excitation of surface plasmon vibrations in $\mathrm{Ag}$ nanoparticles and was evaluated through spectrophotometry at a wavelength range of 350-600 $\mathrm{nm}$. The UVvisible spectra show an absorption band at $448 \mathrm{~nm}$ indicating the presence of spherical Ag nanoparticles.

For gold nanoparticles, bioreduction of $\mathrm{Au}$ ions was observed by visualizing the color change from colorless to dark brown and further absorption band at $551 \mathrm{~nm}$ in UVVisible spectra confirmed the presence of gold nanoparticle in the reaction mixture.

\section{SEM results}

Size and dispersion of the nanoparticles are the important factors for the synthesized samples. The scanning electron microscopy has been engaged to characterization the size, shape and morphologies of formed silver and gold nanoparticles. The SEM images of sample are shown in figure 2 respectively. From the images it is evident that the morphology of AuNP is nearly roughly spherical shaped in cluster and AgNP is indicating spherical. The average particle size analysed with the help of SEM images is observed to be $298 \mathrm{~nm}$ of silver NPs while $105 \mathrm{~nm}$ of gold nanoparticle.

Table.1 Composition of camel milk

\begin{tabular}{|l|l|l|}
\hline Parameter & Nutrional Value & Units \\
\hline Casein Micelles & 320 & $\mathrm{Mm}$ \\
\hline Kappa Casein & 5 & $\%$ \\
\hline Fat & 2 & $\%$ \\
\hline Insulin & 40.5 & $\mu \mathrm{U} / \mathrm{ml}$ \\
\hline Iron & 0.05 & $\mathrm{Mg} / 100 \mathrm{~g}$ \\
\hline Calcium & 132 & $\mathrm{Mg} / 100 \mathrm{~g}$ \\
\hline Potassium & 152 & $\mathrm{Mg} / 100 \mathrm{~g}$ \\
\hline Vitamin C & 35 & $\mathrm{Mg} / \mathrm{l}$ \\
\hline Niacin & 4.6 & $\mathrm{Mg} / 1$ \\
\hline $\begin{array}{l}\text { Peptidoglycan } \\
\text { Recognition Protein }\end{array}$ & 107 & $\mathrm{Mg} / 1$ \\
\hline Omega 7 & 11.6 & $\%$ \\
\hline
\end{tabular}


Fig.1 Bioreduction and colour changes of (A) gold and (B) silver nanoparticles using camel milk

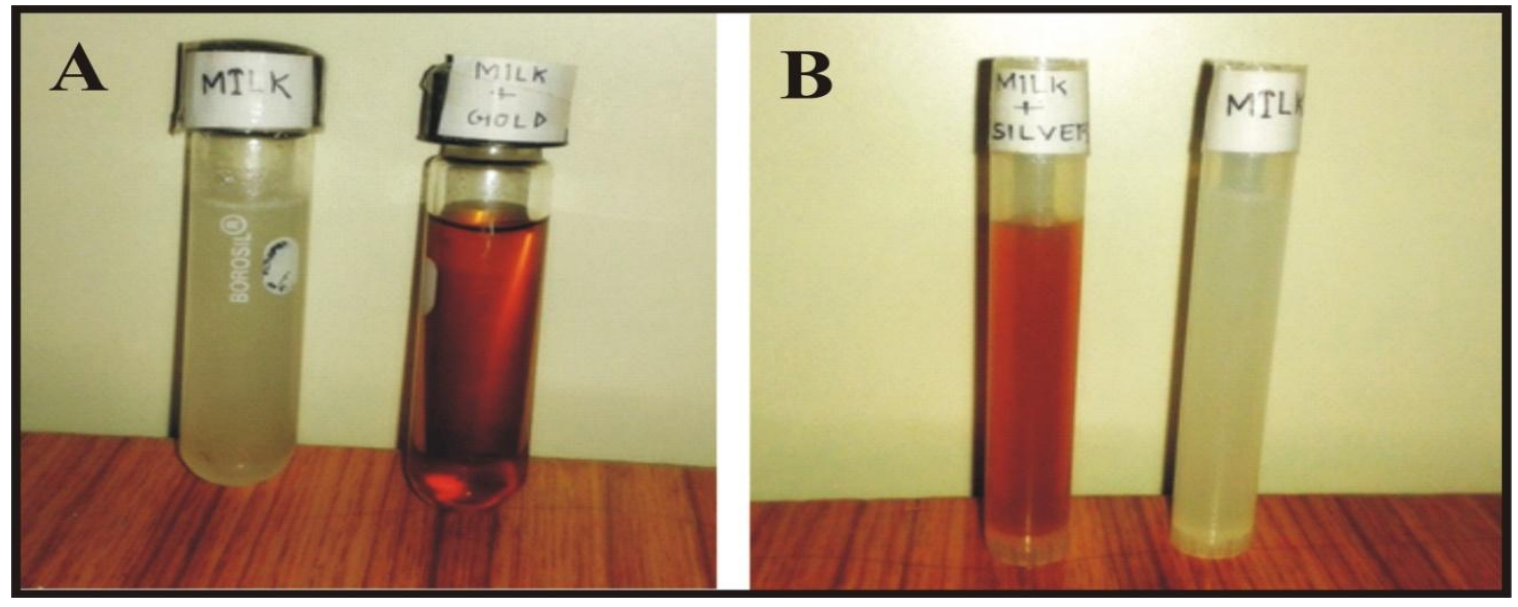

Fig.2 SEM Images of (A) Silver nanoparticles and (B) Gold Nanoparticles

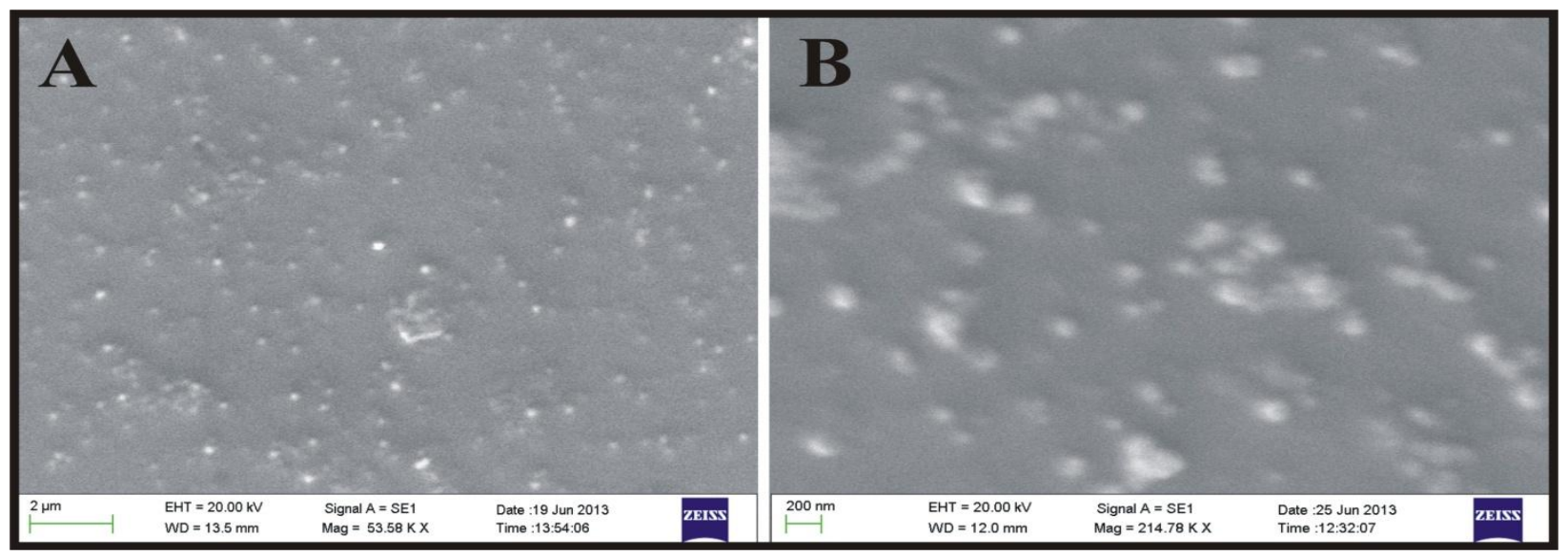

Fig.3 TEM Images of (A) Silver nanoparticles and (B) Gold Nanoparticles

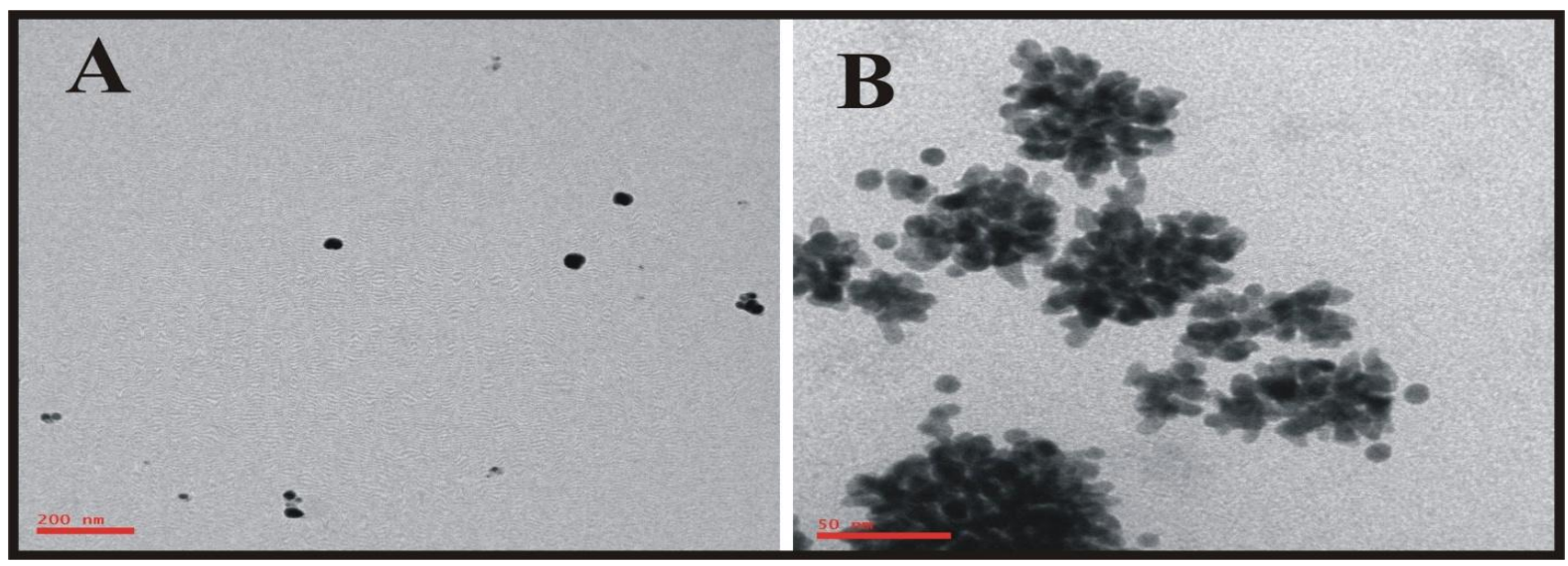


Fig.4 Antibacterial activity against Streptococcus mutans (a) Control

(b) Silver NPs (c) Gold NPs

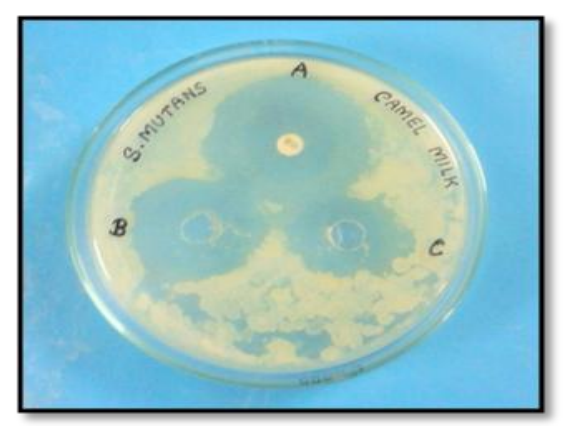

\section{TEM results}

The morphology and the crystal structure of synthesized silver nanoparticles were examined using HR-TEM. The sample was placed on the carbon coated copper grid, making a thin film of sample on the grid and extra sample was removed using the cone of a blotting paper and kept in grid box sequentially. These images suggest that the gold particles are roughly spherical shaped in cluster and silver nanoparticles are mostly spherical in shape. It is evident that there is variation in particle sizes and TEM characterization reveal the size distribution of gold NPs between $100-150 \mathrm{~nm}$ and $298 \mathrm{~nm}$ for the silver NPs. The spherical and roughly spherical shape of the particle, as visible in figure 3 , is due to the fact that when a particle is produced, in its initial state, it tries to obtain a shape that corresponds to minimum potential energy.

\section{Antibacterial activity}

The agar diffusion method was used to notice the effect of the concentrations of both silver and gold against Streptococcus mutans (MTCC 1890) bacteria. The in vitro antibacterial activity of the samples was evaluated by using Mueller-Hinton Agar (MHA). The results as shown that Streptococcus mutans were susceptible to the gold and silver nanoparticle both. The zones of inhibition created by the gold and silver particles of the camel milk compared favorably with control in this study. The activities of gold and silver nanoparticles against $S$. mutans suggested that these particles could be used to treat dental carries (Fig. 4).

In conclusion nanobiotechnology is an important area of research that holds potential application to fight against multidrug-resistant bacteria. This spanking new and simple method for the biosynthesis of silver and gold nanoparticles offers a valuable contribution in the area of nanotechnology.

We have successfully employed for the development of gold and silver nanoparticles with roughly spherical and spherical shapes by using camel milk as reducing and stabilizing agent. The reaction was rapid, economical and can be widely used in biological and medical systems. Synthesis of both gold and silver nanoparticles was studied using UV-Vis spectroscopy, TEM, and SEM analyses.

A silver and gold nanoparticle extracted from camel milk provides antibacterial activity against acid producing bacteria, streptococcus mutans. The use of these NPs in the treatment of dental caries was found to be very effective. Therefore, we proved that this project is successful in reducing dental carries 
further studies must be conducted to test the carcinogenic properties either in animal model or in cell lines in order to evaluate the application of AgNPs and AuNPs as a bactericidal agent.

\section{Acknowledgements}

This research was supported by Department of Science and Technology, Govt. of Rajasthan, Jaipur.

\section{References}

Agamy, E.I., Ruppanner, R., Ismail, A., Champagne, C.P. and Assaf, R. 1992. Antibacterial and antiviral activity of camel milk protective proteins. J. Dairy Res., 59: 169-175.

Allaker, R.P. 2010. The Use of Nanoparticles to Control oral Biofilm Formation. Crit. Rev. Oral Biol. Med., 89(11): 1175-1186.

Brown, S.D., Nativo, P., Smith J.A. 2010. Gold nanoparticles for the improved anticancer drug delivery of the active component of oxaliplatin. J. American Chem. Soc., 132(13): 4678-4684.

Duran, N., Marcato, P.D., Conti, R.D., Alves, O.L., Costa, F.T.M., Brocchi, M. 2010. Potential Use of Silver Nanoparticles on Pathogenic Bacteria, their Toxicity, and Possible Mechanism of Action. J. Braz. Chem. Soc., 21(6): 949-959.

Gopalakrishnan, R., Raghu, K. 2014. Biosynthesis and Characterization of Gold and Silver Nanoparticles Using Milk Thistle (Silybum Marianum) Seed Extract. J. Nanosci.

Holla, G., Yelluri, R.K. 2012. Evaluation of minimum inhibitory and minimum bactericidal concentration of nano-silver base inorganic anti-microbial agent (Novaron $^{\circledR}$ ) against streptococcus mutans. Contemp. Clin. Dent., 3(3): 288-293.

Kumar, A., Kaur, K., Sharma, S. 2013. Synthesis, Characterization and Antibacterial Potential of Silver Nanoparticles by Morus Nigra leaf extract. Indian J. Pharma. Biol. Res., 1(4): $16-24$.

Leaper, D.J. 2006. Silver dressings: their role in wound management. Int. Wound J., 3(4): 282-311.

Manivannan, S. and Ramaraj, R. 2011. Polymerembedded gold and gold/silver nanoparticle-modified electrodes and their applications in catalysis and sensors. Pure and Appl. Chem., 83(11): 2041-2053.

Muthu, M.S. and Wilson, B. 2010. Multifunctional radio nano medicine: a novel nano platform for cancer imaging and therapy. Nanomed., 5(2): 169-171.

Rimal Isaac, R.S., Sakthiwel, G., Murthy, C.H. 2013. Green Synthesis of Gold and Silver Nanoparticles Using Averrhoa bilimbi Fruit Extract. J. Nanotechnol., 6.

Sathishkumar, M., Sneha, K., Won, S.W., Cho, C.W., Kim, S. and Yun, Y.S. 2009. Cinnamon zeylanicum bark extract and powder mediated green synthesis of nanocrystalline silver particles and its bactericidal activity. Colloids and Surfaces B: Biointerfaces, 73(2): 332-338.

Sierra, J.F.H., Ruiz, F., Cruzpena, D.C., Gutierrez, F.M., Martinez, A.E., Guillen, A.J.P., Perez, H.T., Castetanon, G.M. 2008. The antimicrobial sensitivity of Streptococcus mutans to nanoparticles of silver, zinc oxide, and gold. Nanomed., 4(3): 237-240.

Wernery, U. 2007 Camel Milk - New Observations: In Proceedings of International Camel Conference, February 2007.

\section{How to cite this article:}

Kamini Parmar, and Jangir, O.P. 2017. Evaluation and Efficacy of the Antibacterial Activity of Silver and Gold Nanoparticles Synthesize from Camelus dromedarius (Camel) Milk against Oral Pathogenic Bacteria. Int.J.Curr.Microbiol.App.Sci. 6(4): 600-605.

doi: https://doi.org/10.20546/ijcmas.2017.604.072 